@ Copyright 2015 American Meteorological Society (AMS). For permission to reuse any portion of this work, please contact permissions@ametsoc.org. Any use of material in this work that is determined to be "fair use" under Section 107 of the U.S. Copyright Act (17 U.S. Code §?107) or that satisfies the conditions specified in Section 108 of the U.S. Copyright Act (17 USC $\S 108$ ) does not require the AMS's permission. Republication, systematic reproduction, posting in electronic form, such as on a website or in a searchable database, or other uses of this material, except as exempted by the above statement, requires written permission or a license from the AMS. All AMS journals and monograph publications are registered with the Copyright Clearance Center (https://www.copyright.com). Additional details are provided in the AMS Copyright Policy statement, available on the AMS website (https://www.ametsoc.org/ PUBSCopvriahtPolicy).

\title{
Precipitable Water from GPS over the Continental United States: Diurnal Cycle, Intercomparisons with NARR, and Link with Convective Initiation
}

\author{
BASIVI RADHAKRISHNA AND FRÉDÉRIC FABRY \\ Department of Atmospheric and Oceanic Sciences, McGill University, Montreal, Quebec, Canada \\ John J. BRAUn AND TERESA VAN Hove \\ Constellation Observing System for Meteorology, Ionosphere, and Climate Program Office, UCAR, Boulder, Colorado
}

(Manuscript received 19 May 2014, in final form 24 November 2014)

\begin{abstract}
The variation of precipitable water vapor (PW) over the continental United States is examined at various time scales using spatial maps of a column-averaged mixing ratio (CAMR) that is derived from integrated column PW from both observations and reanalysis data. CAMR spatial maps are generated utilizing PW measurements obtained from a network of ground-based global positioning system (GPS) receivers and the North American Regional Reanalysis (NARR) over a time span of 4 yr (February 2009-January 2013). The effect of topography on PW is mitigated by vertically averaging the mixing ratio instead of integrating the absolute humidity. An ordinary kriging interpolation technique is used to generate spatial maps of CAMR. The observed and predicted PW derived by GPS and NARR correlate well with each other at annual and monthly scales. When focusing on its diurnal cycle, moisture peaks in the late afternoon over the Great Plains and late night over the Rockies. It is also found that atmospheric moisture within NARR generally increases in the second half of the UTC day and is adjusted significantly lower when external observations, such as radiosondes, are assimilated into the analysis system. These adjustments in the analysis introduce nonphysical offsets that are not present within the GPS-derived moisture fields. At meso- $\beta$ and meso- $\alpha$ scales, GPS PW fields can be used as a precursor to forecast convection up to $3 \mathrm{~h}$ prior to initiation. As stated previously, the correlation between GPS and NARR is high $(>0.98)$ at monthly and seasonal time scales, but there is poor correlation at time scales less than a day. This indicates that the water budget within NARR is not in proper balance over these short-term time scales. Over the continental United States, daily cycles of PW and precipitation are coupled differently in different areas.
\end{abstract}

\section{Introduction}

Dense and frequent sampling of atmospheric water vapor is of great importance in both climatological research and especially in operational forecasting because water vapor fuels storms. Observations of atmospheric water vapor are primarily made through radiosondes and ground- or space-based radiometers. Though radiosondes measure atmospheric water vapor profiles with good accuracy, these measurements are limited in space and time (Wang et al. 2000). Thus, radiosonde measurements are not sufficient to study the spatial and

Corresponding author address: Dr. B. Radhakrishna, Dept. of Atmospheric and Oceanic Sciences, McGill University, 805 Sherbrooke St. West, Montreal QC H3A 2K6, Canada.

E-mail: rakibasivi@gmail.com temporal variability of water vapor across a range of scales. On the other hand, ground-based radiometers experience problems during rainy periods, while spacebased radiometer measurements degrade in the presence of clouds (Derks et al. 1997). While the spatial coverage of water vapor measurements is improved through the use of observations (Randel et al. 1996), its temporal sampling remains poor.

Measurements from global positioning system (GPS) satellites can be used to sense the atmosphere by measuring the refraction and delay of the signals as they pass through the atmosphere. These delays can then be used to infer column-integrated precipitable water vapor or precipitable water (PW) (Bevis et al. 1992, 1994; Rocken et al. 1993, 1997). When a network of GPS stations is available, they can substantially improve the spatial and temporal coverage of humidity above the surface and 
can even be used to generate spatial maps of PW. The nucleus of the GPS network used in this study is SuomiNet (Ware et al. 2000). It was originally a university-based, real-time, national GPS network developed for atmospheric research and education, but it now includes additional stations operated by a variety of partners including the National Oceanic and Atmospheric Administration (NOAA), the U.S. Coast Guard and U.S. Army Corps of Engineers (USCG/USACE), multiple state Department of Transportation (DOT) agencies, the NOAA National Geodetic Survey (NGS) Continuously Operating Reference Station (CORS) network, and the Plate Boundary Observatory (PBO). More accurately, SuomiNet now represents an analysis system within the COSMIC Program of the University Corporation for Atmospheric Research that is dedicated to supporting the research and education community.

GPS satellites broadcast signals on two L-band radio frequencies $(1575.42 \mathrm{MHz}$ for $\mathrm{L} 1$ and $1227.6 \mathrm{MHz}$ for L2). These signals are delayed as they pass through the troposphere. This so-called tropospheric delay is related to the integral of refractivity through the atmosphere. Refractivity is a function of pressure, temperature, and water vapor pressure. The total atmospheric delay can be separated into a hydrostatic term and a wet term (Haase et al. 2003). The hydrostatic term can be calculated using a surface pressure measurement (Saastamoinen 1972; Davis et al. 1985). The wet term, related to the induced dipole moment of atmospheric water vapor, is then estimated within GPS analysis software packages as a state parameter with adjustable time resolution. This wet delay can be scaled to its equivalent columnintegrated PW (Duan et al. 1996) with an accuracy of $1 \mathrm{~mm}$ over the continental United States (Alber et al. 1997). Studies by Dumont and Zabransky (2001), Brown et al. (2002), and Dai et al. (2002) showed a high level of agreement between the integrated PW values estimated from the GPS receivers, radiosondes, and microwave radiometers. However, these studies also portray that the ground-based GPS receivers are slightly underestimating the integrated PW values when compared with PW values obtained from radiosondes and microwave radiometers. A statistical comparison study by Nahmias and Zabransky (2004) showed a high correlation between the PW values estimated from wet delays and the meteorological observed data. Recent improvements made in the retrieval of $\mathrm{PW}$ are described in Braun and Van Hove (2005).

Dai et al. (2002) studied the diurnal variation of precipitable water over different regions of United States utilizing data from 54 ground-based GPS stations. This study is mainly focused over the central United States and has found good agreement in the mean diurnal variations derived from the GPS PW data with those derived from the sounding and microwave radiometer (MWR) data at Lamont, Oklahoma. Comparing the diurnal cycle of PW with the surface rain obtained from rain gauge measurements at 10 stations, they showed that the PW and precipitation are in phase at few stations in central United States and out of phase at other stations. Utilizing rain gauge data (Dai et al. 1999) and radar maps (Carbone et al. 2002; Davis et al. 2003; Carbone and Tuttle 2008; Surcel et al. 2010), researchers have shown a distinct diurnal cycle of precipitation during the summer season over various regions of the United States.

Over the continental United States, GPS stations are numerous enough to resolve meso- $\alpha$-scale and some meso- $\beta$-scale features of precipitable water. With four years of data available from more than 500 stations in and around the continental United States archived centrally, one can start to look in a more coherent manner at average properties, climatological patterns, cycles, and intercomparisons, as well as perform conditional sampling under specific circumstances. We have chosen to do a bit of all of the above. After a brief description of the GPS PW data (section 2) and their transformation into spatial maps column-averaged mixing ratios (section 3), we will look at annual cycles and interannual variability of water vapor as revealed by such datasets compared to what could be derived from reanalyses (section 4). Similar comparisons will also be made with the diurnal cycle, and we will explore the link between these cycles and those of the occurrence of convection (section 5). Finally, we will contrast humidity and precipitation occurrence patterns as well as humidity patterns prior to convective initiation against those under average conditions (section 6) in an attempt to gauge the usefulness of GPS-derived precipitable water patterns for climatological studies and forecasting.

\section{Data}

The present study utilizes PW measurements from GPS stations with a time resolution of 30 min over a time span of $4 \mathrm{yr}$ (i.e., from February 2009 to January 2013). All GPS data were analyzed at UCAR using the Bernese Global Navigation Satellite Systems (GNSS) Analysis software, version 5.0 (Dach et al. 2007), using an ionosphere-free double-difference network strategy. Satellite orbits and earth rotation parameters from the International GNSS Service (IGS) rapid solutions (Dow et al. 2009) were used throughout the analysis. Station coordinates were constrained to the IGS realization of the 2008 International Terrestrial Reference Frame (Rebischung et al. 2012). All available observations 
down to $5^{\circ}$ elevation were used. A priori hydrostatic delays from Saastamoinen (1972) were computed using surface pressure measurements either from collocated sensors or with surface observations obtained within $50 \mathrm{~km}$ of a station. For stations that were not collocated with a surface pressure instrument, corrections based on differences in instrument altitudes were computed to remove errors in the hydrostatic delay calculations. Direct mapping functions based on ray tracing through the Global Forecast System (Rocken et al. 2001) were used to model the hydrostatic delays within the analysis. Absolute antenna phase center calibrations (Schmid et al. 2007) provided by the IGS were used for all antennas.

Between the SuomiNet GPS stations and those from other partners, 503 GPS stations are available in the contiguous United States, southern Canada, and northern Mexico to generate maps of PW. This is roughly 8 times more than the number of radiosondes, with measurements being made 24 times more often, allowing us to retrieve PW at meso- $\alpha$ resolution (Fig. 1). The complex topography over the continental United States alters the depth of the column of integration for PW, from which we can expect a negative correlation between PW and ground-level altitude. Attempts to interpolate PW between stations will hence be strongly affected by the effects of the topography. To mitigate these effects on PW, we chose to analyze and interpolate fields of column-averaged mixing ratio (CAMR) instead. The CAMR values are obtained as follows:

$$
\mathrm{CAMR}=\frac{1000 \mathrm{PW}}{P g^{-1}},
$$

where PW, $P$, and $g$ are the GPS-derived precipitable water in millimeters, the surface pressure in pascals, and the acceleration due to gravity in meters per second squared, respectively. The estimated values of CAMR using (1) are more independent from topography than PW because CAMR is the ratio of the topographymodulated mass of vapor to the similarly topographymodulated mass of dry air over the given column of integration. The estimated mixing ratio values using (1) at all the available stations are utilized to generate the spatial maps employing an ordinary kriging technique over the continental United States with a spatial resolution of $0.25^{\circ} \times 0.25^{\circ}$ and a temporal resolution of $30 \mathrm{~min}$. Note that the available number of stations used in the generation of spatial maps varies with time as the number of reporting stations varies over time. The effective spatial resolution will also be similarly variable, dictated by the actual density of the reporting stations around any given location. CAMR values estimated from (1) slightly overestimate when there is a weather

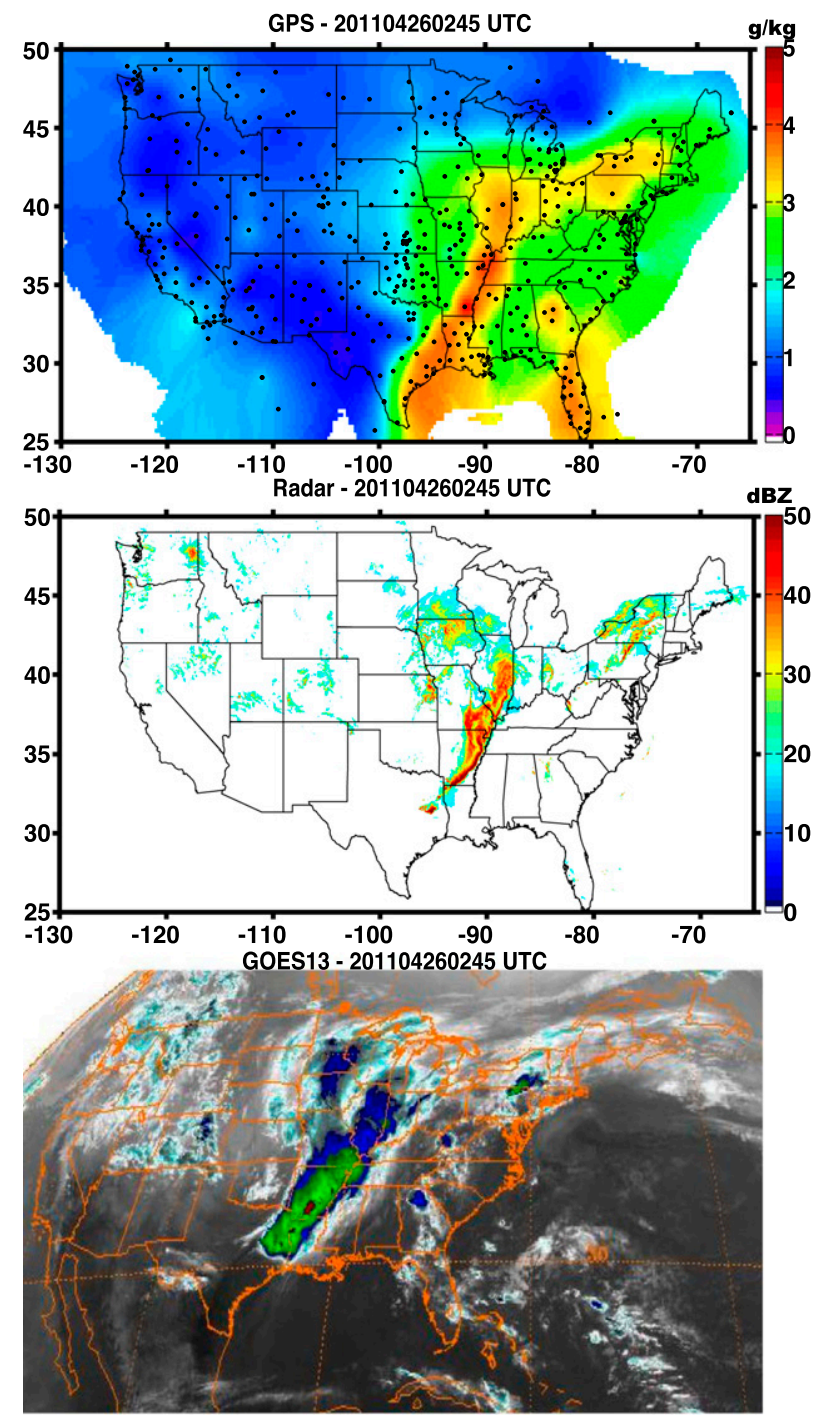

FIG. 1. Comparison between (top) the spatial map of CAMR obtained using the ordinary kriging interpolation, (middle) the low-level radar reflectivity, and (bottom) the GOES-13 thermal IR imagery at 0245 UTC 26 Apr 2011. The overlaid dots in the top panel indicate locations of GPS stations from the SuomiNet and its partners. In the GPS-derived CAMR map, the warm and cold fronts of this large weather system can be clearly identified.

event. For example, a 10-hPa change in pressure alters the CAMR value by $1 \%$, which is negligible when compared with the diurnal cycle of CAMR shown in section 5 .

Before generating the spatial maps, we checked the quality of the data by estimating the surface pressure from the altitude information of each station; we discarded the data that are reporting pressure values not within the range of $\pm 10 \%$ of the estimated pressure values to eliminate data blunders. We also compared the mean pressure at each station with the estimated pressure at that station and found that one station was 
reporting $\sim 20 \mathrm{hPa}$ less pressure than its expected average, leading to its elimination from our analysis. In this data quality checking process, we also noticed that most of the stations' data are missing between 2230 UTC and midnight. To handle data gap issues and their possible effect on retrievals, we filled the data gaps that are less than or equal to $2 \mathrm{~h}$ in time by linearly interpolating CAMR data in time for each station before generating the spatial maps. Longer gaps were left as such.

To validate and compare the spatial maps of CAMR obtained from the SuomiNet observations, we used analyses fields from the North American Regional Reanalysis (NARR; Mesinger et al. 2006). NARR combines data from different sources: pressure from surface observations; winds from radiosondes, pibals, dropsondes, and aircraft measurements; cloud drift winds from geostationary satellites, etc. The primary source of moisture data assimilated into NARR originates from twice-daily radiosondes. The present study utilizes 4 yr of NARR data spanning from February 2009 to January 2013 with a temporal resolution of $3 \mathrm{~h}$. The original $32 \mathrm{~km} \times 32 \mathrm{~km}$ spatial resolution NARR data are interpolated to $0.25^{\circ} \times 0.25^{\circ}$ to match the CAMR maps of GPS receivers.

To understand the link between PW and near-surface precipitation, we also utilize the Warning Decision Support System-Integrated Information (WDSS-II) generated low-altitude radar reflectivity data. The spatial coverage of the radar network extends from $20^{\circ}$ to $52^{\circ} \mathrm{N}$ and from $130^{\circ}$ to $60^{\circ} \mathrm{W}$. Reflectivities below $15 \mathrm{dBZ}$ are ignored to remove echoes from nonmeteorological targets. The WDSS-II radar composite data are remapped to a spatial resolution of $0.25^{\circ} \times 0.25^{\circ}$ (eastwest and north-south) to match with CMIR maps of GPS receivers and NARR model predictions. Though WDSS-II provides low-altitude radar reflectivity maps with a time resolution of $5 \mathrm{~min}$, we considered only two maps in each hour, one $15 \mathrm{~min}$ after the hour and the other $45 \mathrm{~min}$ after the hour, to match with the timing of GPS network data.

\section{Ordinary kriging interpolation}

To interpolate the data from many GPS stations, we relied on kriging interpolation (Tabios and Salas 1985). Kriging interpolation is similar to optimal interpolation except that the spatial correlation function is replaced by a variogram. To perform a kriging interpolation, a second-order stationary process is required. Ordinary kriging assumes a wide sense stationarity of the field; that is, this technique assumes homogeneity in the means, variances, and covariances. Ordinary kriging interpolation is mathematically described in Tabios and
Salas (1985). The kriging weights $\lambda_{i}$ are computed using the following equation:

$$
\left[\begin{array}{c}
\lambda_{1} \\
\vdots \\
\lambda_{n} \\
\mu
\end{array}\right]=\left[\begin{array}{cccc}
\gamma\left(d_{11}\right) & \cdots & \gamma\left(d_{1 n}\right) & 1 \\
\vdots & \ddots & \vdots & \vdots \\
\gamma\left(d_{n 1}\right) & \cdots & \gamma\left(d_{n n}\right) & 1 \\
1 & \cdots & 1 & 0
\end{array}\right]^{-1}\left[\begin{array}{c}
\gamma\left(d_{01}\right) \\
\vdots \\
\gamma\left(d_{0 n}\right) \\
1
\end{array}\right],
$$

where the subscript $n$ indicates the total number of stations within a radius of $5^{\circ}$ in latitude/longitude from the center of the grid point, $\mu$ represents a Lagrange multiplier, and $\gamma\left(d_{i j}\right)$ is the semivariogram as a function of the distance $d_{i j}$ between the stations $i$ and $j$, defined as

$$
\left.\gamma\left(d_{i j}\right)=\frac{1}{k-1} \sum \mathrm{CAMR}_{i}-\mathrm{CAMR}_{j}\right]^{2},
$$

with $k$ denoting the total number of simultaneous CAMR observations from stations $i$ and $j$. Since we are interpolating CAMR values to a grid point, a model semivariogram $\gamma\left(d_{0 i}\right)$ is generated utilizing the CAMR variograms of all the stations that are in a $5^{\circ}$ radius from the center of the grid. An arbitrary $5^{\circ}$ radius is chosen to have a sufficient number of points in generating the model variogram by fitting a power law of the form $\gamma\left(d_{0 i}\right)=A \times\left(d_{0 i}\right)^{B}$. From the variogram matrices, the kriging weights $\lambda$ applied to the available stations are computed using (3); these are then used to obtain the interpolated CAMR values thanks to the following equation:

$$
\mathrm{CAMR}_{\text {interpolated }}=\sum_{i=1}^{n} \lambda_{i} \mathrm{CAMR}_{i} .
$$

The output of the ordinary kriging technique of CAMR at 0245 UTC 26 April 2011 is shown in Fig. 1. Also shown in Fig. 1 are the WDSS-II low-altitude radar reflectivity map and Geostationary Operational Environmental Satellite-13 (GOES-13) IR radiance. It is apparent from Fig. 1 that the interpolated CAMR map shows a good resemblance with both the radar-observed reflectivity map and the GOES-13 radiance. Maps such as these are generated for every $30 \mathrm{~min}$ over a 4 -yr period and form the dataset for the analyses to follow. Since we used a $5^{\circ}$ radius for interpolation, the PW values went far from the coast, but we restricted our analysis to land regions only.

\section{Annual and seasonal variations of CAMR}

The annual mean and standard deviations of the CAMR spatial maps obtained from the ground-based GPS network and NARR over the continental United 

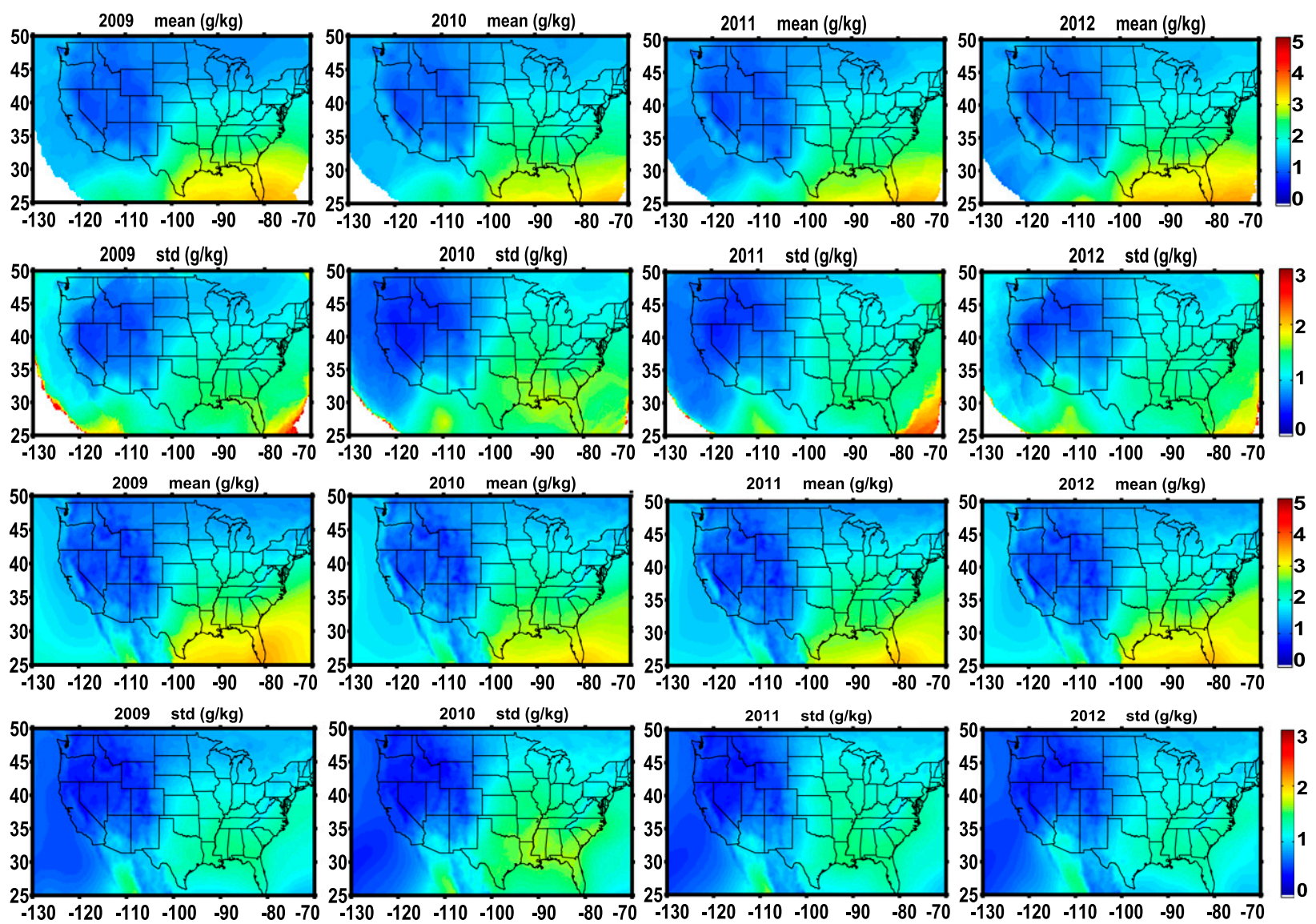

FIG. 2. Annual mean and standard deviation maps of CAMR obtained from (top) SuomiNet GPS observations and (bottom) NARR over the continental United States between February 2009 and January 2013.

States are shown in Fig. 2. The small standard deviation values over the Rockies and western United States indicate less variability in CAMR throughout the year when compared to the Great Plains and the coastal lowlands of the United States. The large standard deviations seen outside the United States in Fig. 2 are artifacts mainly because of the smaller number density of the observations. Thus, the comparisons shown in the present study are restricted to an analysis domain within $30^{\circ}-50^{\circ} \mathrm{N}, 120^{\circ}-80^{\circ} \mathrm{W}$. If one compares the mean CAMR of the observations from the ground-based GPS receivers network and reanalysis from NARR in Fig. 2, one finds that they are generally very similar, as further suggested by the high cross correlation (0.98) and low RMS difference $\left(\sim 0.12 \mathrm{~g} \mathrm{~kg}^{-1}\right)$ between the two at the annual scale.

The spatial and temporal variability of CAMR is discussed in detail with the help of seasonal mean CAMR maps. Figure 3 illustrates the seasonal mean CAMR maps of GPS and NARR. In Fig. 3, we can identify many expected patterns. The continent as a whole is drier during winter [December-February
(DJF)] when compared with the spring [March-May (MAM)], summer [June-August (JJA)], and fall [September-November (SON)] seasons. The low-level jet starts transporting the moisture from the Gulf of Mexico to the Great Plains during the month of April, in turn increasing the CAMR. The moisture penetrates deeper into the continent during summer months and decreases during the fall. Examining CAMR variability at the monthly scale (not shown), it is found that, during the month of April, CAMR values increase over a confined region (Texas, Oklahoma, and Arkansas) of the continental United States. This is mainly as a result of the transport of moisture by the low-level jet from the Gulf of Mexico. The penetrated moisture starts spreading from May to September over the Great Plains and along the east coast of the United States. Similar to this, the North American monsoon (Adams and Comrie 1997) starts transporting the moisture from the Gulf of California to the Arizona region during July-September, which explains the observed high annual mean and standard deviations over the southern part of Arizona (Fig. 2). The availability of moisture in large amounts 

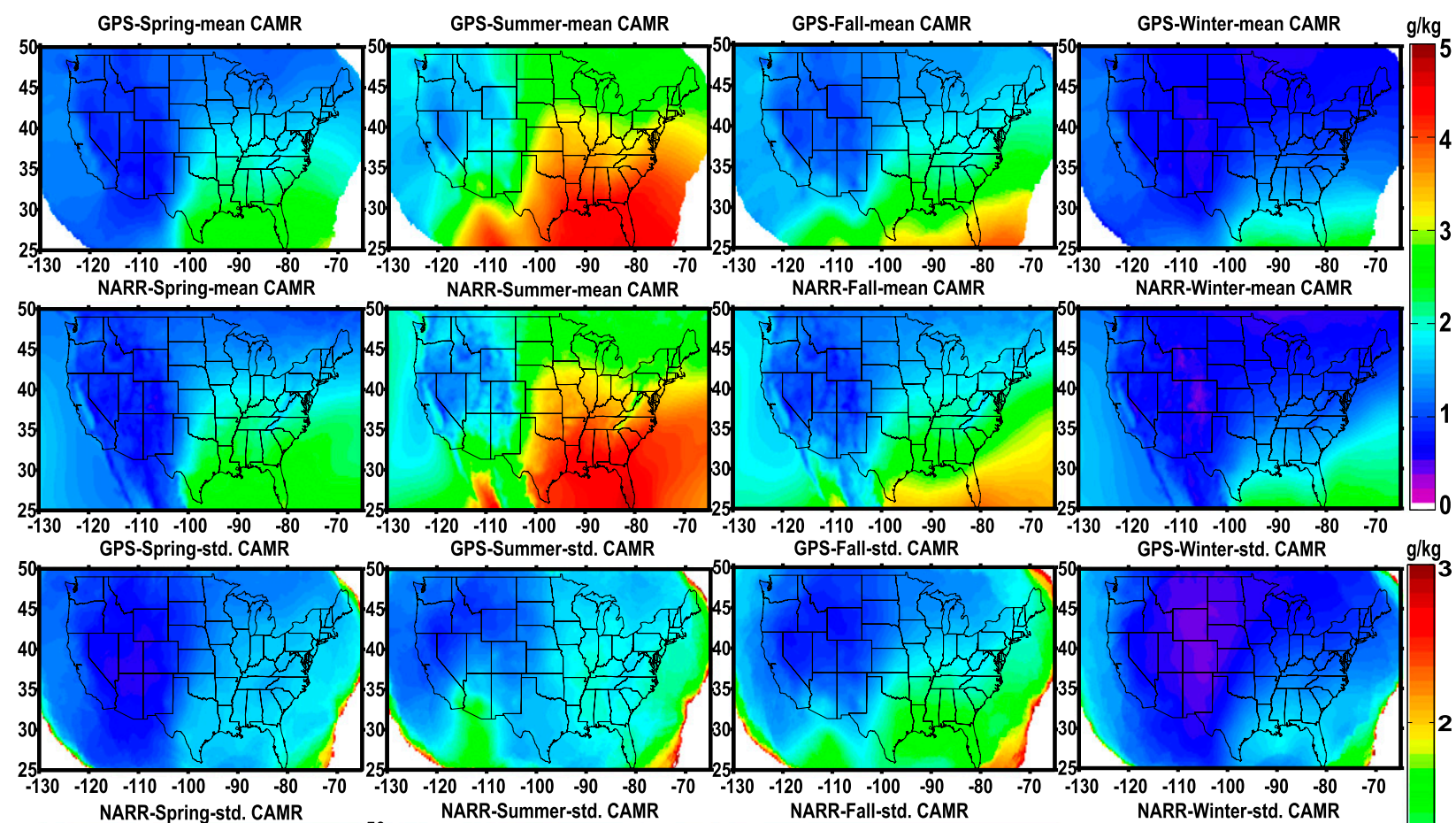
GPS-Winter-std. CAMR

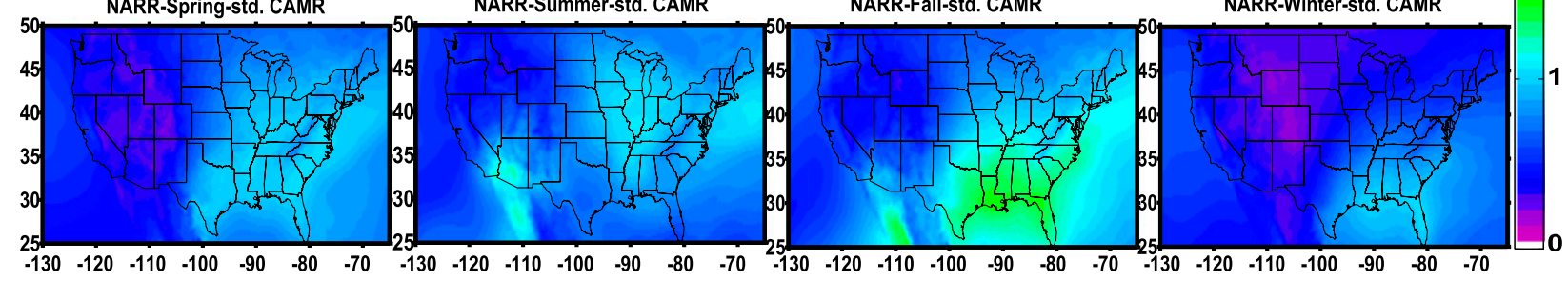

FIG. 3. (top) Seasonal mean and (bottom) standard deviation maps of CAMR obtained from GPS observations and NARR over the continental United States.

over different parts of the United States during these months favors the formation of thunderstorms.

The bias in annual mean CAMR between GPS and NARR is illustrated with the help of Fig. 4. The positive bias in Fig. 4 indicates the overestimation of CAMR values by GPS when compared with NARR and vice versa. From Fig. 4, we can see that except over highterrain regions, GPS is underestimating the CAMR values by approximately $0.1 \mathrm{~g} \mathrm{~kg}^{-1}$, or close to $5 \%$, when compared with NARR. This is not a new result: Dai et al. (2002) had compared the PW derived from groundbased GPS receivers with radiosonde data and PW measured by microwave radiometers (Braun and Van Hove 2005) and showed that the ground-based GPS receivers underestimate the $\mathrm{PW}$ by approximately $1 \mathrm{~mm}$. Since the main data source from NARR is radiosondes (Ciesielski et al. 2014), the underestimation of CAMR values by ground-based GPS receivers in the regions with low orography concurs with the findings of Dai et al. (2002). The cause of this bias remains unknown. Over high terrain, a sampling effect is added: the
GPS receivers generally measure lower surface pressure values than expected from the model grid point at that location, as they are more often located at the tops of mountains rather than in valleys. Thus, from (2), though the observed PW values are small, the low pressure values results in high CAMR values and in turn the overestimation of CAMR by ground-based GPS receivers.

\section{Diurnal variation of CAMR}

The diurnal cycle of moisture over a given region is a result of the combined effect of the transport of moisture, evaporation, and precipitation. As the CAMR shows two distinct distributions over the continent (low CAMR values over the Rockies and western United States and high CAMR values over the eastern side of the Rockies), we divided the analysis region into two subregions to represent the mean diurnal cycle. Region 1 covers the Rockies and the western United States between $120^{\circ}$ and $100^{\circ} \mathrm{W}$. Region 2 extends from the eastern side of the Great Plains to the Midwest, 

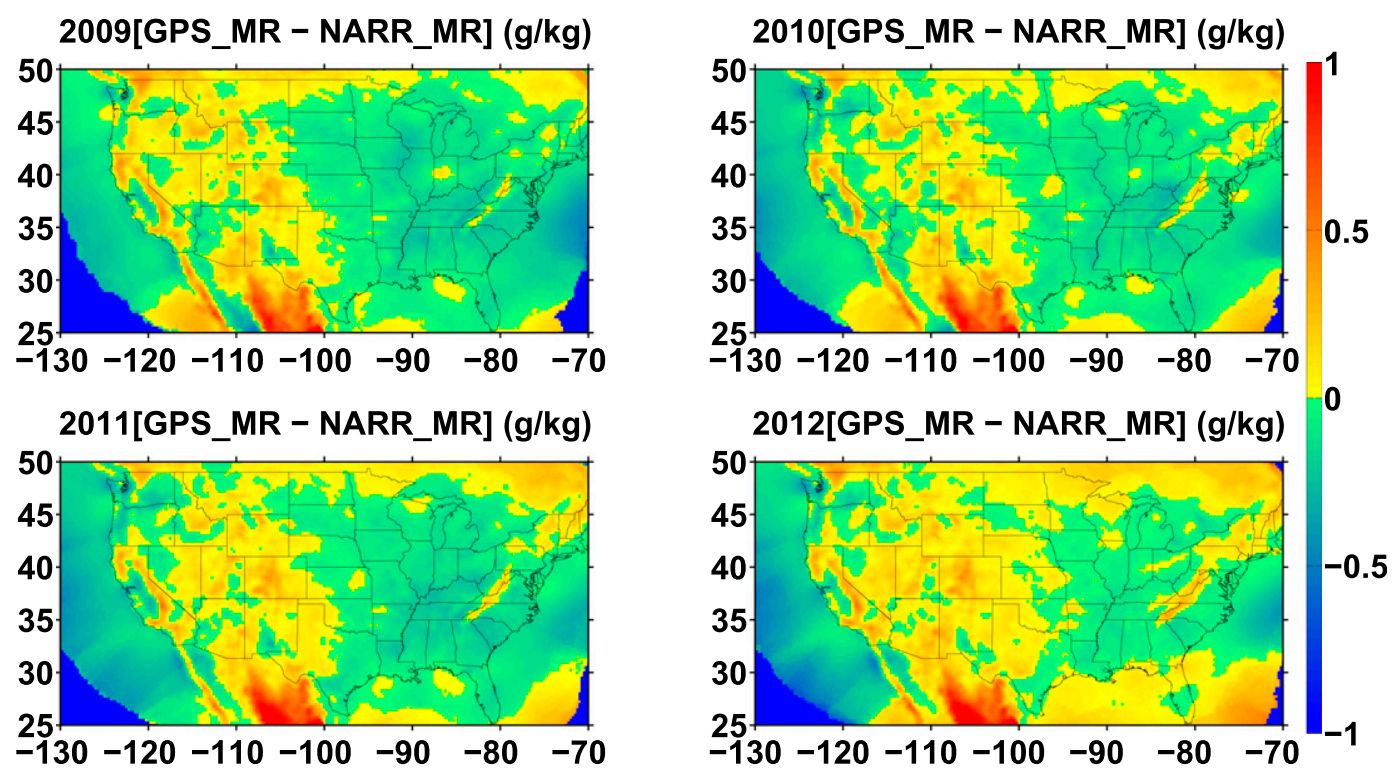

FIG. 4. Bias in annual mean CAMR between GPS and NARR. Positive values indicate the overestimation of GPS when compared with NARR and vice versa.

spanning between $100^{\circ}$ and $80^{\circ} \mathrm{W}$. Figure 5 depicts the seasonal-mean diurnal anomalies of CAMR of GPS (solid line) and NARR (dotted line) for the two regions. The diurnal cycle of moisture obtained from the GPS products is well correlated in time (i.e., from one month to another month), though with varying diurnal amplitudes. Also, the diurnal cycle of CAMR peaks near the middle of the night (around 0600 UTC) in region 1
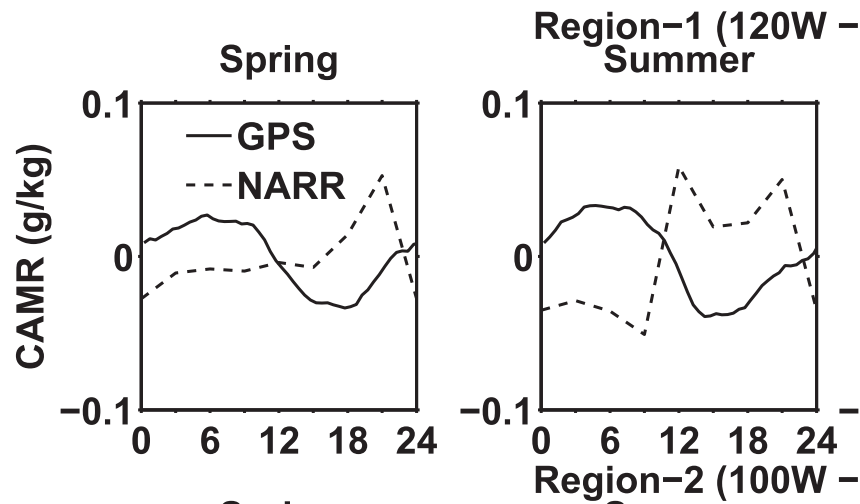

$-100 W \& 30 N-50 N)$
Fall
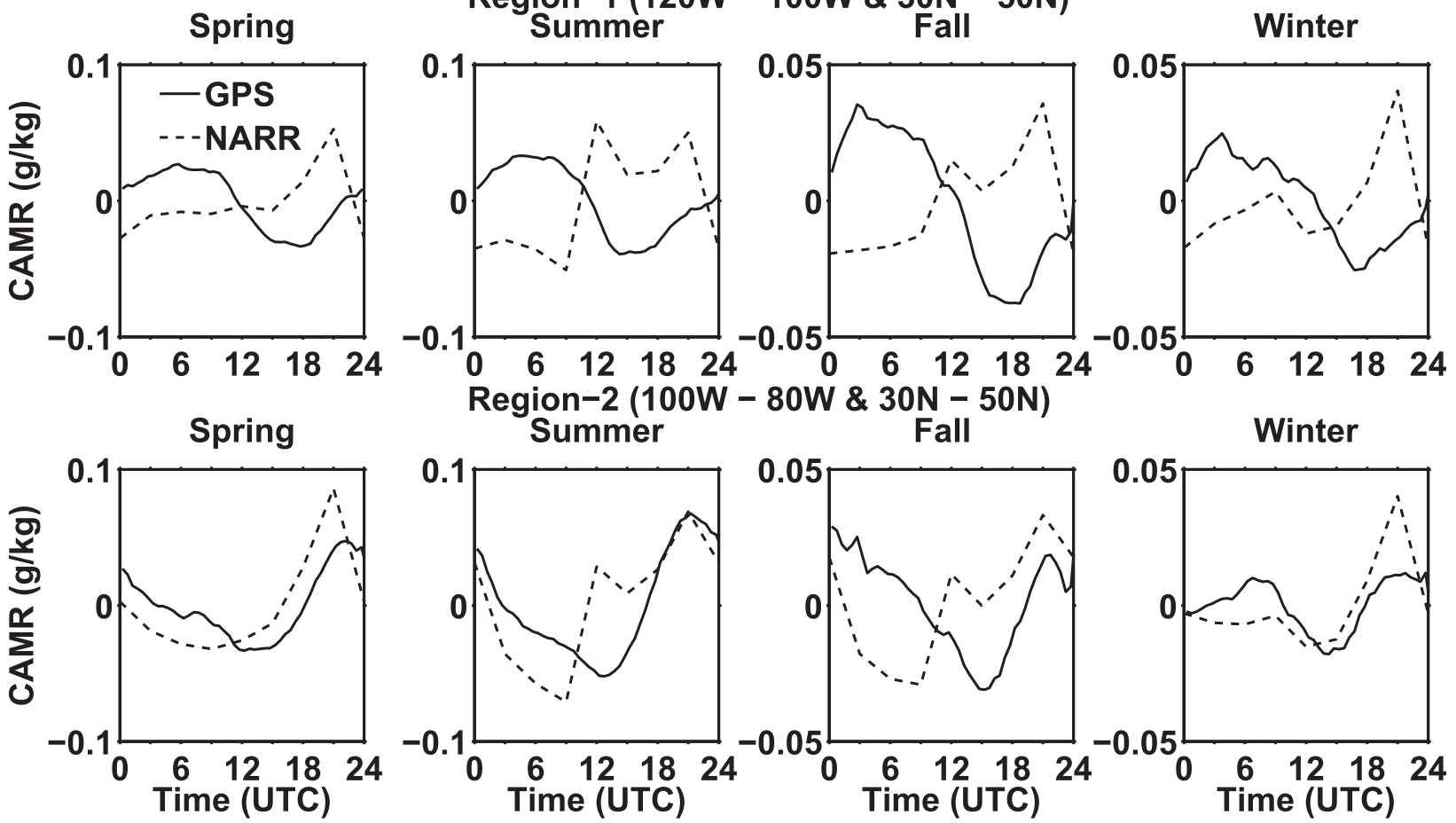

FIG. 5. Diurnal cycle of mean CAMR from GPS and NARR for spring (MAM), summer (JJA), fall (SON), and winter (DJF) for (top) region 1 and (bottom) region 2. The average diurnal anomalies are estimated for the period between February 2009 and January 2013 in the respective seasons. 
(western sector) and in late afternoon (around 0000 UTC) in region 2 (eastern sector).

The diurnal cycles of moisture within the NARR and observed with the GPS are fairly well correlated in region 2 and poorly correlated in region 1 , which suggests that NARR is not simulating the diurnal cycle properly over the Rockies and western United States. Furthermore, the previously observed bias between GPS and NARR appears to be systematic in region 2 for all months. On the other hand, except during the winter months, NARR underestimates CAMR values in region 1. The diurnal cycle within the NARR also shows sudden jumps (offsets) at the times of data assimilation (1200 and 0000 UTC) in both regions. During the daytime (i.e., after 1200 UTC), CAMR values from the reanalyses are found to increase with time and reach their maximum value at 2100 UTC and then drop suddenly at 0000 UTC. Some of this drop is likely as a result of an adjustment of the reanalysis by the assimilation of new data at 0000 UTC. The plausible mechanisms of increasing CAMR during the day could be due to either excessive surface evaporation (Dai et al. 1999) or improperly accounting for the transport of moisture and for precipitation. These are only inferences and are not discussed in detailed because we lack independent information to evaluate which term of the water budget is not computed properly in the reanalysis.

That being written, the warm season diurnal cycle of precipitation captured through observations over the Great Plains and along the east coast of the United States (Dai et al. 1999; Carbone et al. 2002; Davis et al. 2003; Carbone and Tuttle 2008; Surcel et al. 2010) seems to be well represented in the reanalysis, as the correlation between GPS and NARR is high during this season (Fig. 5) in region 2. Though the reanalysis properly captures the warm season diurnal cycle, large adjustments in CAMR are still observed at the time of data assimilation. In region 2 , these discontinuities at the times of data assimilation are stronger in winter and spring at 0000 UTC and in summer and fall at 1200 UTC. These discontinuities are also stronger in region 1 than in region 2. Thus, it appears that the water budget within the NARR does not correctly simulate the diurnal cycle over the continental United States.

The peak-to-peak variation (in grams per kilogram) and time of peak occurrence (in UTC) in the diurnal cycle of CAMR at each grid point over the continental United States during summer season is shown in Fig. 6. The bottom panel of Fig. 6 represents the peak occurrence time (in UTC) of convection observed by the U.S. radar network. This map is generated utilizing the radar mosaics, with reflectivity greater than $40 \mathrm{dBZ}$ as a proxy for convection. The convective peak occurrence shows

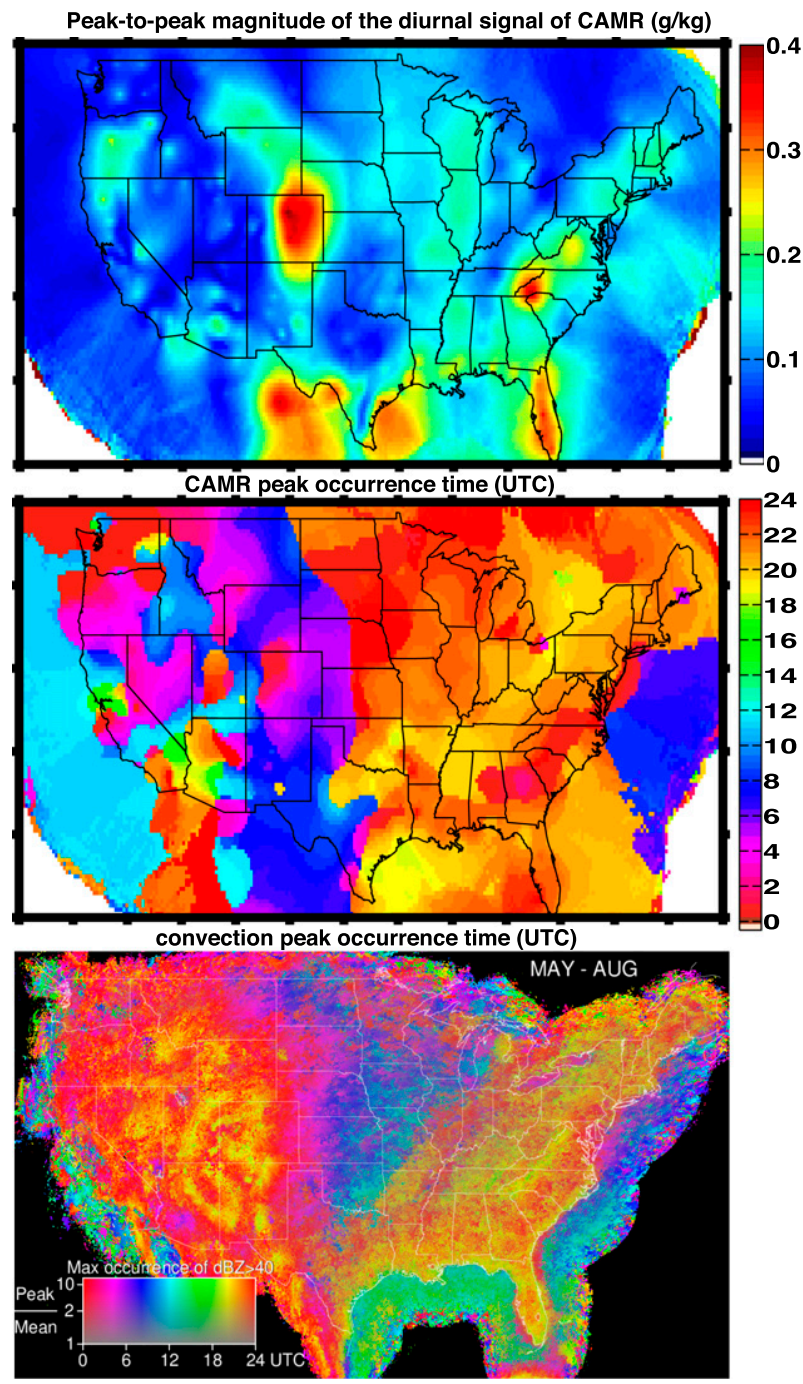

FIG. 6. Comparison between maps of (top) the peak-to-peak magnitude of the diurnal cycle in CAMR, (middle) the time of occurrence of the peak in CAMR, and (bottom) the time of peak occurrence of radar echoes of convective intensity during the summer season. In the bottom panel, brighter colors correspond to strong diurnal cycles in the occurrence of convection, while duller colors signify weaker peaks.

that convection originates around 2000 UTC over the Rockies and is transported to the Great Plains and central plains throughout the night (Carbone et al. 2002; Carbone and Tuttle 2008). The magnitude of the diurnal cycle of CAMR also peaks around $105^{\circ} \mathrm{W}$ and along the east coast regions of the United States in the mid- to late afternoon, but the daily peak in CAMR does not seem to move eastward from the Rockies, as convection does. The large variability in the diurnal amplitudes of CAMR around $105^{\circ} \mathrm{W}$ seen in Fig. 6 is likely related to the local origin of convection and its associated precipitation (Carbone et al. 2002; Carbone and Tuttle 2008; Surcel 

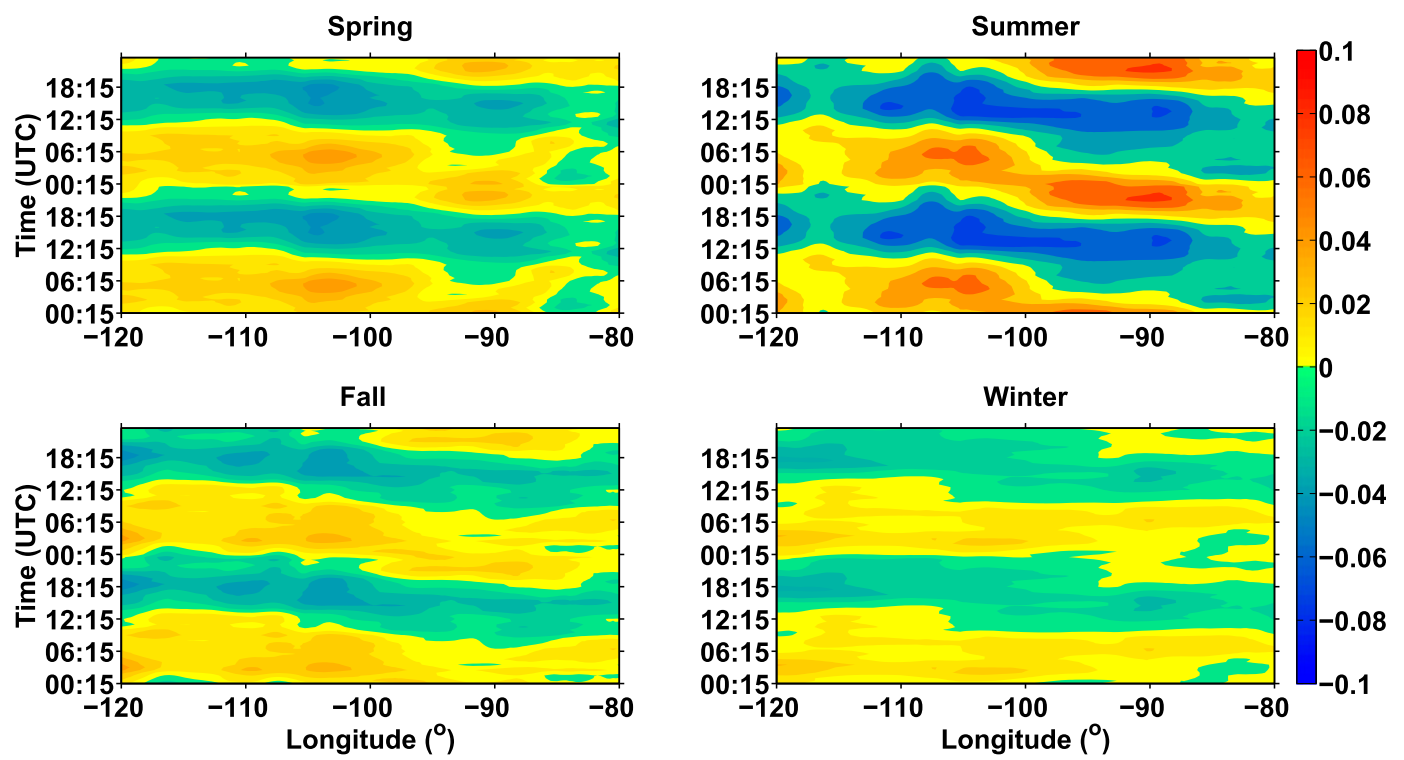

FIG. 7. Hovmöller diagrams of the deviation of CAMR $\left(\mathrm{g} \mathrm{kg}^{-1}\right)$ from the daily mean obtained from the GPS data during each season.

et al. 2010). Along the coastal regions, particularly along the Gulf coast, the land and sea breezes and the locally generated convection produce variations in the $\mathrm{PW}$, and in turn in CAMR, that lead to large variations in the diurnal amplitudes.

A time-longitude analysis was conducted to provide better insight into how CAMR varies spatially. Carbone et al. (2002) and Surcel et al. (2010) performed a similar analysis using rainfall fields that helped illustrate how rainfall patterns had a preference for propagating zonally rather than meridionally across the continental United States. This propagation can be explained by the relative strength of the zonal winds compared to the meridional winds. Here, we used 30-min time averages of GPS-derived CAMR at each longitude within a latitudinal range of $30^{\circ}-50^{\circ} \mathrm{N}$. Hovmöller diagrams of the deviation of CAMR from the daily mean were created for each season and are shown in Fig. 7. The dominant feature is the diurnal cycle across seasons. A clear diurnal cycle of CAMR is apparent with large variability in space and time. During fall (SON), winter (DJF), and spring (MAM), the Hovmöller plots of CAMR suggest that the moisture is transported from west to east starting at around $100^{\circ} \mathrm{W}$ following the low-level westerly winds (Dai and Deser 1999) over a period of 2-3 days. On the other hand, a similar transport of moisture is not clearly observed from the Rockies to the Great Plains during the warm season (JJA) even though it has been previously observed within precipitation episodes (Carbone et al. 2002; Carbone and Tuttle 2008; Surcel et al. 2010). The variation in amplitude of the CAMR diurnal pattern is strong during April and September (not shown) with a maximum amplitude in the month of June and becoming relatively weak in the remaining months.

To compare the observed CAMR diurnal cycle in time-longitudinal coordinates, a similar time-longitude analysis was carried out on the NARR data and is represented in Fig. 8. The NARR-resolved diurnal cycle also contains a west-to-east transport of moisture originating around $105^{\circ} \mathrm{W}$ during the spring (MAM) and fall (SON) seasons and near $90^{\circ} \mathrm{W}$ during the winter season. There is no clear transport during the summer season, especially during July and August (not shown). Irrespective of season, the subdaily variation in CAMR within the NARR has a maximum at 2100 UTC with an additionally strong signal present at 1200 UTC between $110^{\circ}$ and $98^{\circ} \mathrm{W}$ during the summer (JJA) and possibly fall (SON). These large maxima at 2100 UTC and also the presence of strong signal at $1200 \mathrm{UTC}$ between $110^{\circ}$ and $98^{\circ} \mathrm{W}$ during June-September are responsible for the observed sharp gradients in the mean diurnal cycle shown in Fig. 8. Thus, the diurnal cycle predicted by NARR in time-longitude coordinates is distinctly different from that of GPS.

The similarities and dissimilarities in the diurnal cycle of CAMR observed by GPS and predicted by NARR are discussed in detail with the help of scale analysis. The scales are decomposed utilizing the twodimensional fast Fourier transform (2D-FFT). Twodimensional FFTs are made of the Hovmöller diagrams of deviation of CAMR shown in Figs. 7 and 8 to obtain amplitudes at each time scale and are shown in Figs. 9 

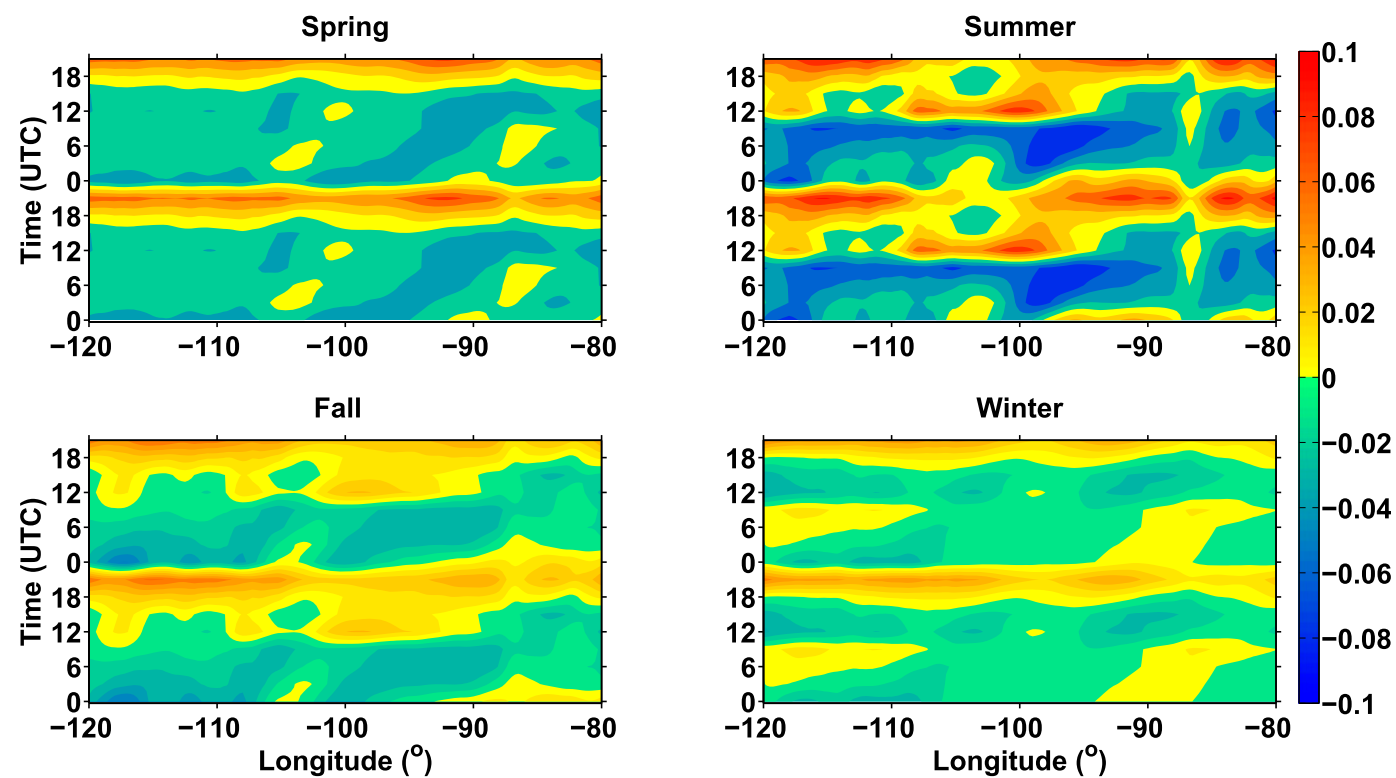

FIG. 8. As in Fig. 7, but for CAMR obtained from NARR.

and 10. The amplitudes represented in Figs. 9 and 10 are normalized with respect to its peak amplitude at each longitude. The scale analysis of GPS observations shows a strong diurnal $(24 \mathrm{~h})$ signal during all seasons. The only exception is near $85^{\circ} \mathrm{W}$ during the winter and spring seasons where a semidiurnal signal $(12 \mathrm{~h})$ dominates the diurnal signal. The spectral analysis of the diurnal signal within NARR is distinctly different. There is a much stronger semidiurnal cycle that is observed at almost all latitudes and during all seasons. Thus, though the CAMR values match well at annual and monthly scales, the diurnal cycle predicted by NARR is distinctly different from the observations (GPS). The scale analysis of observed and predicted CAMR results clearly indicates that the water budget at the diurnal scale is poorly recreated in the NARR.
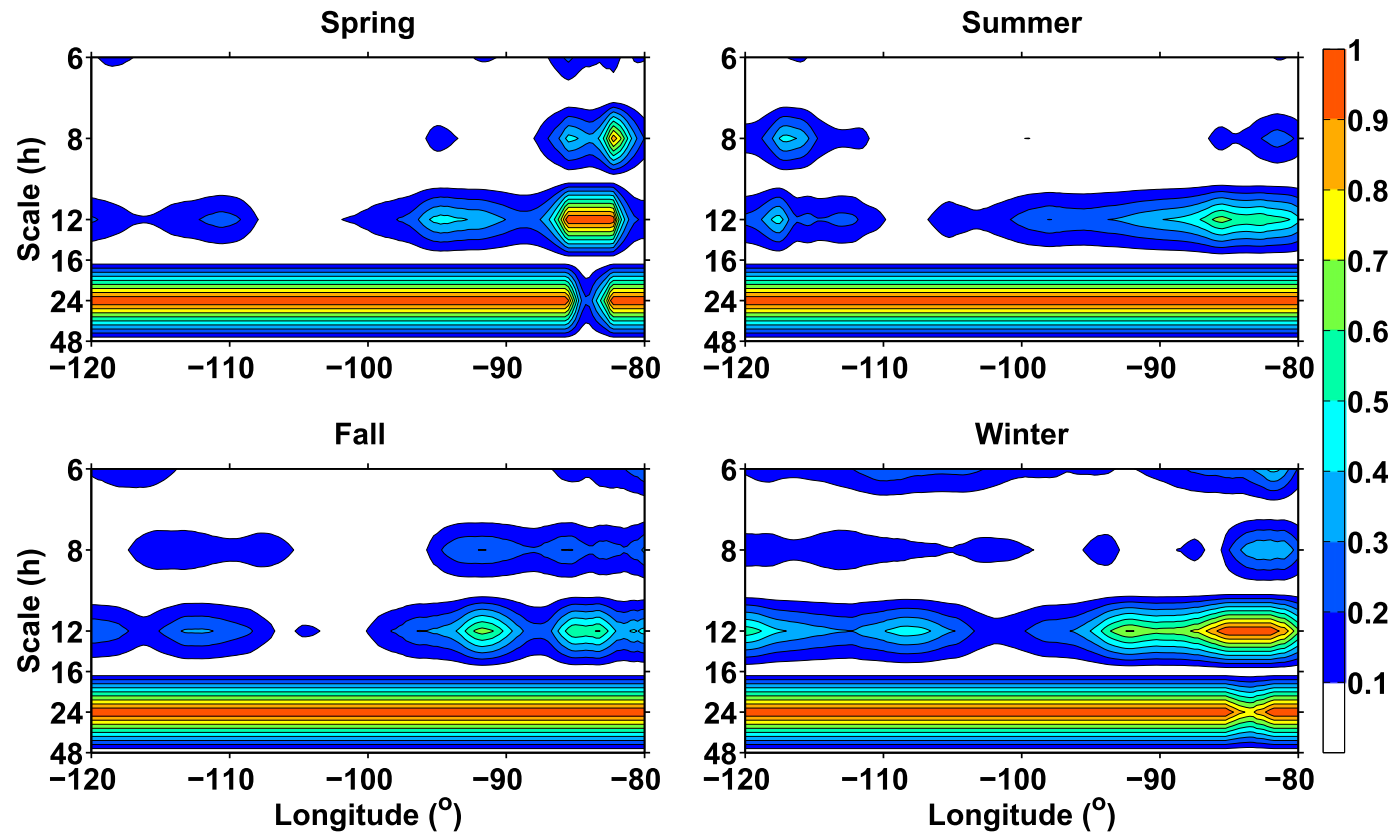

FIG. 9. Normalized power spectra of the Hovmöller diurnal cycle shown in Fig. 7. The scales are decomposed in the spectral space utilizing an FFT. 

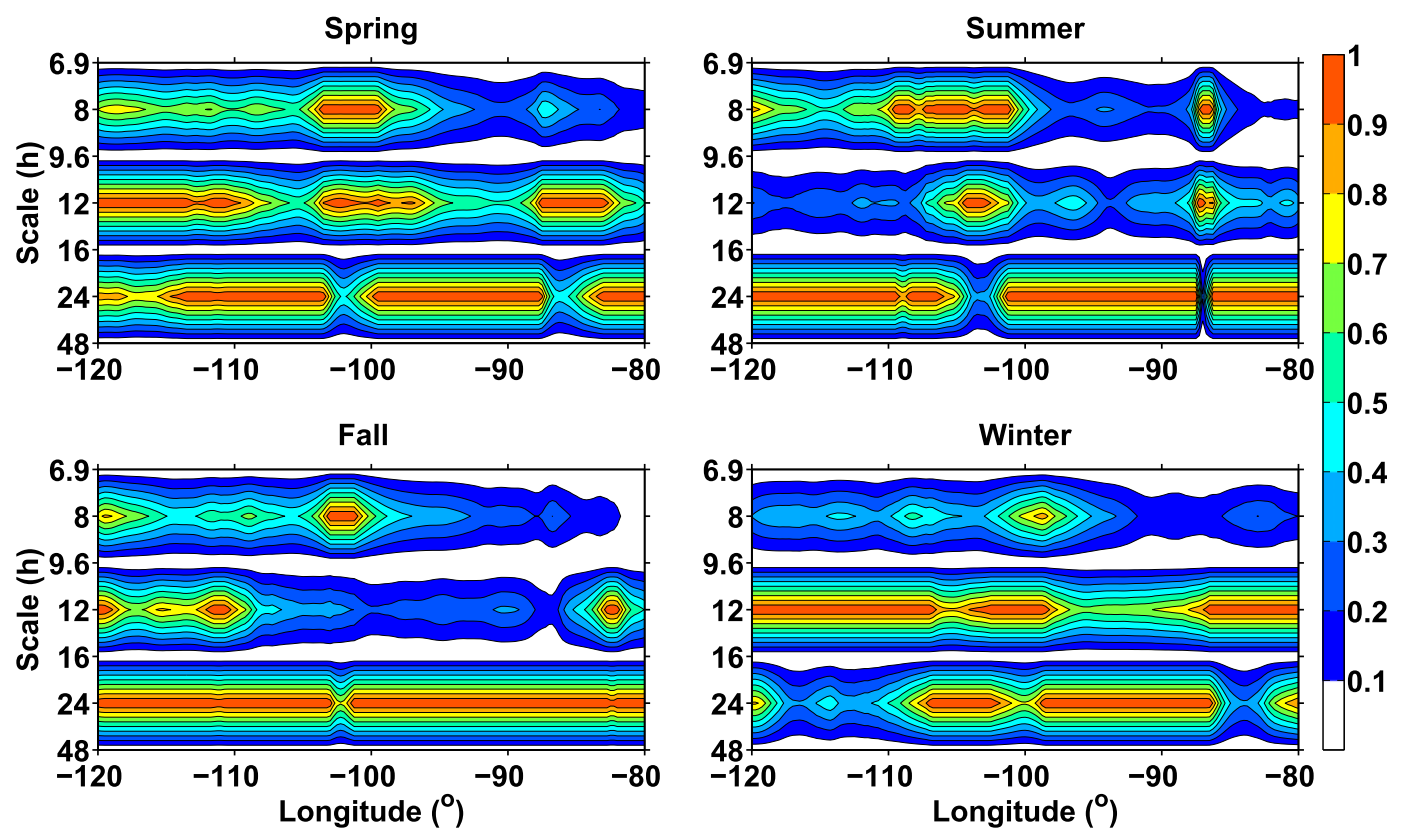

FIG. 10. Normalized power spectra of the Hovmöller diurnal cycle shown in Fig. 8.

\section{Humidity and precipitation}

\section{a. Diurnal cycles of $P W$ and precipitation}

PW and precipitation are interconnected in the atmosphere through evapotranspiration from the surface, evaporation from lakes and oceans, moisture transport, condensation, and precipitation. The link between PW and precipitation is examined by utilizing the low-altitude radar reflectivity maps from WDSS-II and the GPS-derived CAMR maps generated over the continental United States. The Hovmöller diagrams of occurrence of rainfall for each season are shown in Fig. 11. Similar to the previous studies (Carbone et al. 2002; Carbone and Tuttle 2008; Surcel et al. 2010), the most predominant feature is the eastward propagation of precipitation that originates around $105^{\circ} \mathrm{W}$ and moves
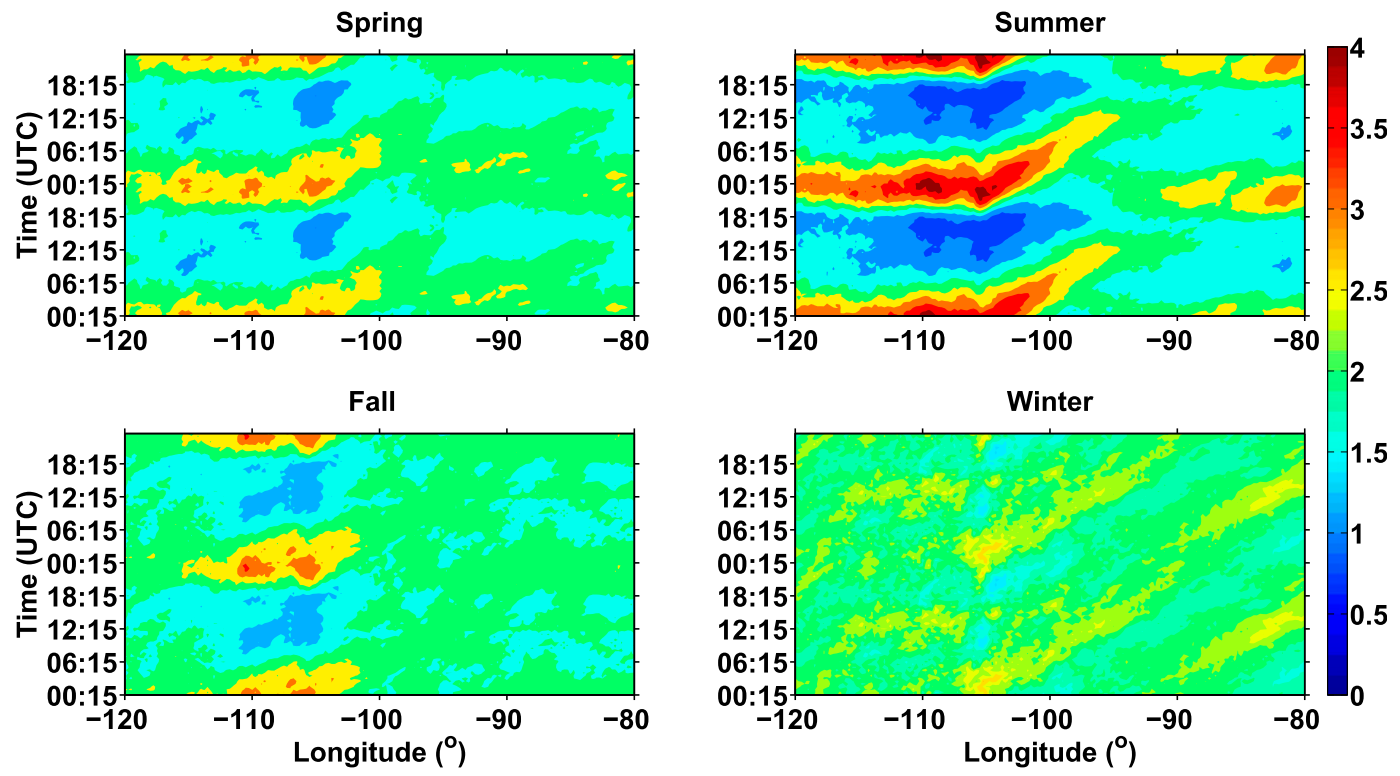

FIG. 11. Hovmöller diagrams of occurrence of rainfall (\%) during each season obtained from the WDSS-II low-altitude radar composites from February 2009 to January 2013. 

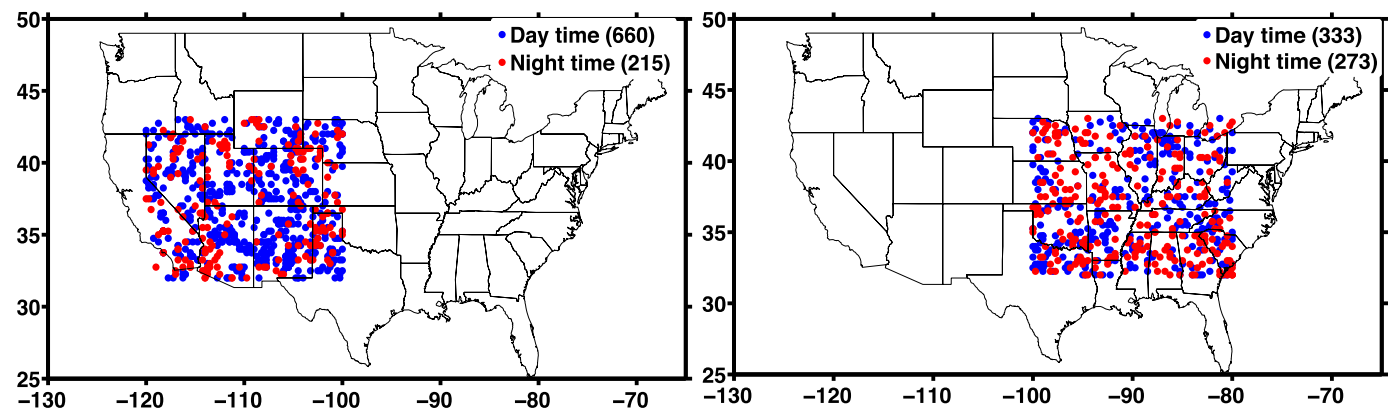

FIG. 12. Convective initiation locations obtained from radar composites during May and August from 2009 to 2012 over (left) region 1 and (right) region 2. The blue dots indicate daytime initiations and red dots indicate nighttime initiations. The number of convective initiation points obtained during these periods is indicated in parentheses.

into the Great Plains. As mentioned in section 5, this transport feature is not seen in the GPS-derived CAMR (Fig. 7). Less pronounced eastward propagation patterns are also visible during the winter, spring and summer seasons, but with a time period of 2-3 days.

A secondary feature within the diurnal rainfall is the relative maximum that occurs at $90^{\circ} \mathrm{W}$ and extends east. In contrast to the rainfall pattern that originates around $105^{\circ} \mathrm{W}$, this pattern aligns relatively well with the diurnal cycle of CAMR from the GPS (Fig. 7). In this case, the atmospheric moisture and rainfall are generally in phase over the broader eastern United States during the summer season.

On the other hand, over the Rockies $\left(115^{\circ}-105^{\circ} \mathrm{W}\right)$, a different relationship between precipitation and CAMR is observed. In this region, the occurrence of rainfall tends to increase from 1200 through 0000 UTC and then rapidly decrease. In contrast, the CAMR maximum for this region does not occur until approximately 0600 UTC. Dai et al. (2002), using station data from Platteville, Colorado $\left(40.2^{\circ} \mathrm{N}, 104.7^{\circ} \mathrm{W}\right)$, also showed similar features but at a single station. The reason for the continued increase in moisture following precipitation in this geographical region is unclear. It could be because of either (or both) the transport of moisture or strong evaporation (from either the surface or in the atmospheric column before precipitation reaches the ground). Both of these processes add moisture to the column of the atmosphere and contribute to the increase in CAMR. The decrease in CAMR values after 0600 UTC over the Rockies can likely be attributed to the prevalence of downward motion in the region. This large-scale motion is due to the mountain-plains solenoid circulation over the Rockies and is well documented in the literature (Carbone and Tuttle 2008). This circulation acts to flush moisture from the column of the atmosphere over the mountains after 0600 UTC, resulting in a decrease in CAMR values. The diurnal cycle of CAMR and the occurrence of rainfall shown in Figs. 7 and 11 illustrate that the PW and precipitation are not coherently linked across time and space. This indicates that additional information is needed to accurately describe the water budget across the continental United States.

\section{b. PW patterns and convective initiation}

To complete our exploration of the information available in GPS-derived humidity maps, we chose to explore whether specific patterns of CAMR maps at the meso- $\beta$ and meso- $\alpha$ scales were associated with convective initiation $(\mathrm{CI})$. To achieve this, we first identified clear cases of convective initiation with the help of radar mosaics during May and August (summer convection). Convective initiation is identified as follows. We first identify the pixel groups with radar reflectivities $(Z)>40 \mathrm{~dB} Z$ and select the pixel with the maximum reflectivity within a $10^{\circ}$ latitude-longitude radius as the point of initiation. These steps are repeated to identify the number of observations that include convection within the selected domain (i.e., $30^{\circ}-45^{\circ} \mathrm{N}, 120^{\circ}-80^{\circ} \mathrm{W}$ ). After identifying the pixels with significant convection, we evaluated the radar reflectivity in the maps $1 \mathrm{~h}$ before in the nearby region with a $2^{\circ}$ radius. Within this region, if all pixels have $Z<30 \mathrm{~dB} Z$, then the convective pixel is identified as the location of convective initiation. The $2^{\circ}$ radius was selected to avoid instances where convective initiation had occurred in previous hour that may have moved into the analysis domain. To check the impact of precipitable water on convective initiation, a $5^{\circ}$-radius CAMR map centered at the initiation location is considered at the times of initiation and $3 \mathrm{~h}$ before. To avoid the common area between the adjacent convective initiation points, pixels having $Z>40 \mathrm{~dB} Z$ within a $10^{\circ}$ radius are discarded initially. The identified convective initiation locations in regions 1 and 2 are shown in Fig. 12. Daytime is considered to be between 0800 and 2000 LT and nighttime is considered to be between 2000 and 0800 LT . It is interesting to note that in region 1 , the onset of convection was preferable during the daytime $(n=660)$ over high 


\section{Region-1 CAMR (g/kg)}

Day time
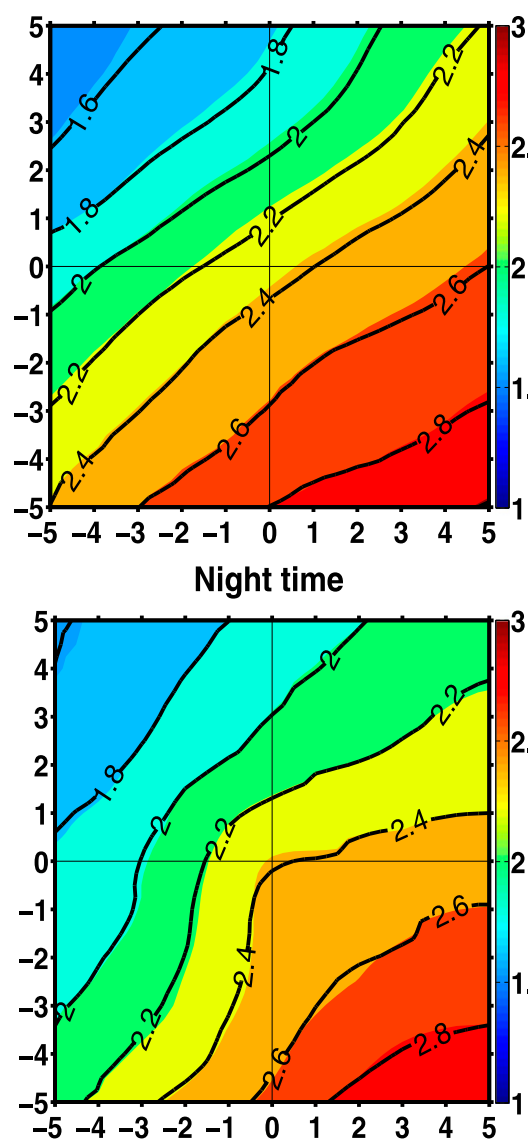

Mean state (day)

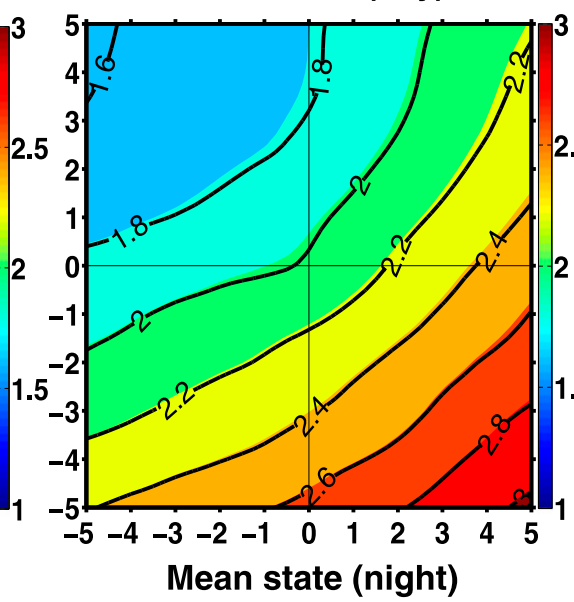

Deviation from mean state (day)

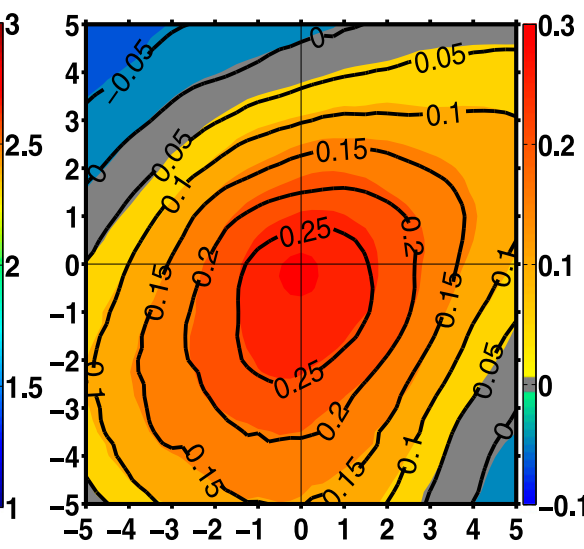

Deviation from mean state (night)

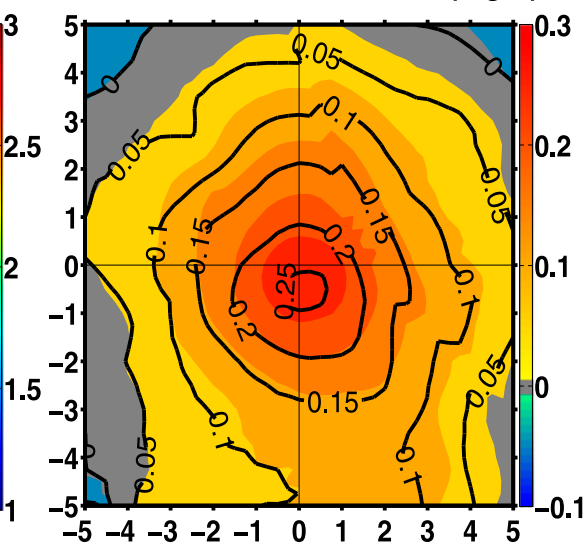

FIG. 13. Composite CAMR maps associated with convective initiation in region 1 for (top) day and (bottom) night. (left) CAMR map at convective initiation (color shading) and 3-h before (contours), (center) CAMR mean state map at the same location, and (right) the difference between convective initiation days and the mean state.

terrain and during the nighttime $(n=215)$ over the plains. Region 2 displays no clear preference between daytime $(n=333)$ and nighttime $(n=273)$ initiation events.

To know how different these CAMR maps are from the background mean state in the identified convective initiation regions, monthly mean CAMR maps are generated at different times of the day with a time resolution of $30 \mathrm{~min}$. The background mean state is constructed by utilizing these monthly mean CAMR maps at different times by averaging the $5^{\circ}$-radius CAMR maps centered at the convective initiation points at the times of initiation and $3 \mathrm{~h}$ before. For example, let us consider a convective initiation point at $35^{\circ} \mathrm{N}, 95^{\circ} \mathrm{W}$ for 2000 LT in May and a $5^{\circ}$-radius CAMR map selected from $35^{\circ} \mathrm{N}, 95^{\circ} \mathrm{W}$ for 2000 and $1700 \mathrm{LT}$. These CAMR maps at all convective initiation locations are used to estimate the background mean state at the time of initiation and $3 \mathrm{~h}$ before initiation, respectively. The mean CAMR maps at the times of convective initiation and $3 \mathrm{~h}$ before initiation, along with their corresponding background mean state CAMR maps during daytime and nighttime in regions 1 and 2, are presented in Figs. 13 and 14 , respectively. The color-shaded contours in Figs. 13 and 14 show the mean CAMR maps at the time of convective initiation and the black contours indicate the mean CAMR maps at $3 \mathrm{~h}$ before the initiation. Also shown in Figs. 13 and 14 are the deviations from the background mean state at these two times.

From Figs. 13 and 14, it is obvious that, at the time of convective initiation, a clear enhancement in the column-averaged moisture field exceeding $0.25 \mathrm{~g} \mathrm{~kg}^{-1}$ is observed over the surroundings of the initiation location when compared with the background mean state. This enhancement is significant when compared with the diurnal signal of CAMR whose amplitude is less than $0.15 \mathrm{~g} \mathrm{~kg}^{-1}$. In region 1 , the CAMR pattern is similar to the background mean state during the daytime except for the increase in moisture nearby the initiation 
Day time
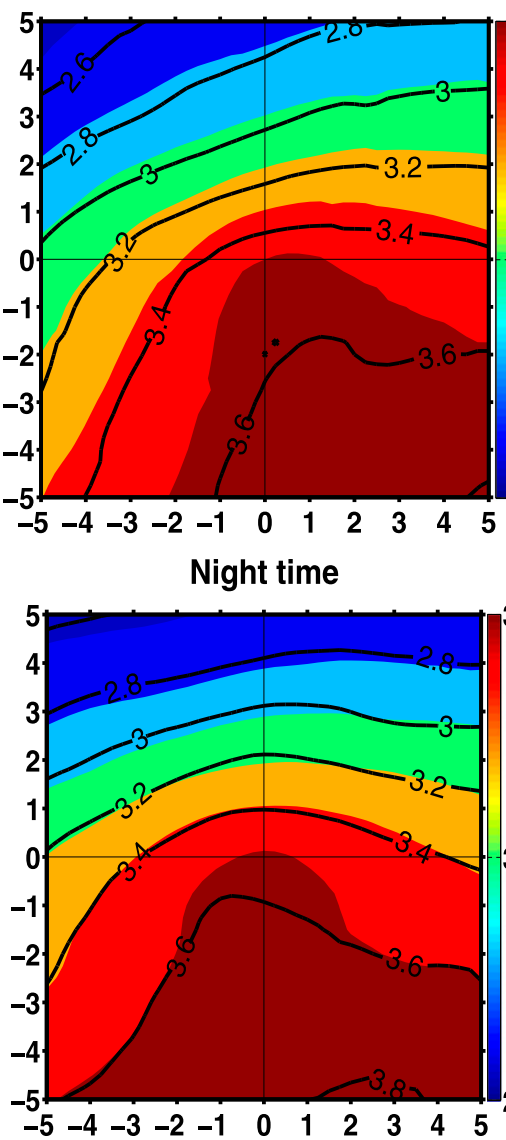

Region-2 CAMR (g/kg)

Mean state (day)
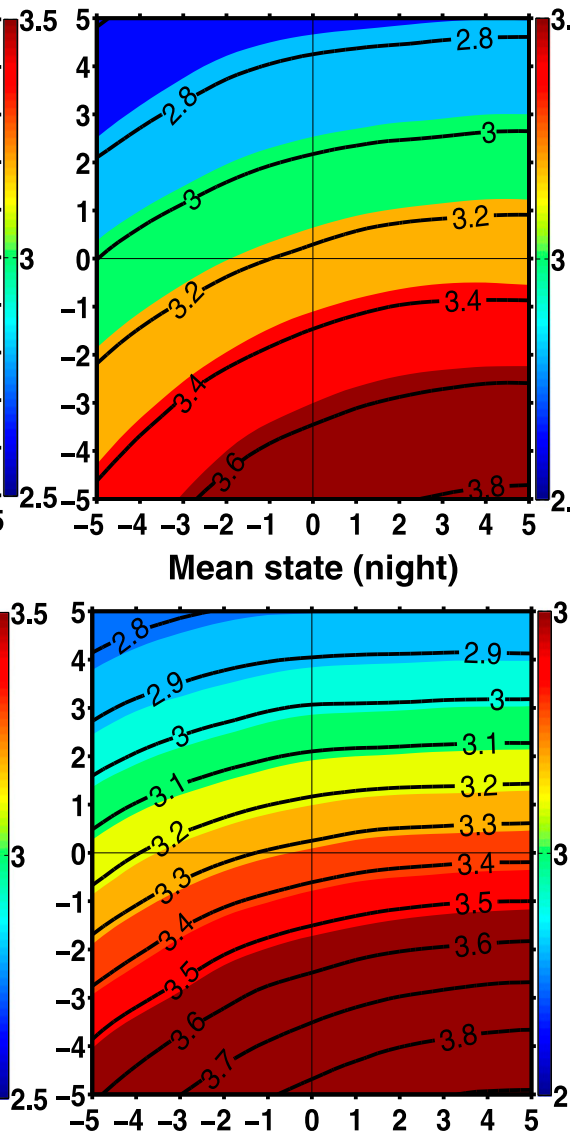

Deviation from mean state (day)

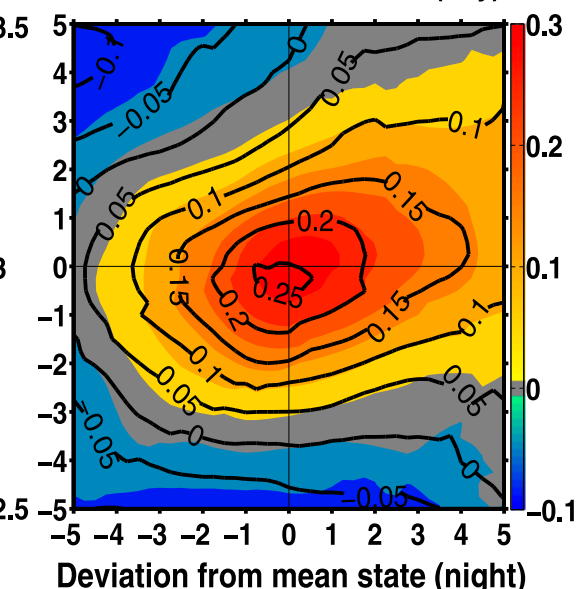

FIG. 14. As in Fig. 13, but for region 2.

location. On the other hand, during the nighttime, the pattern of CAMR in region 1 is distinctly different from the mean state and is similar to the pattern of CAMR in region 2 . This change in pattern is clearly visible $3 \mathrm{~h}$ before initiation. This pattern signature is useful for identifying convective initiation during the nighttime in region 1 . When compared with the mean state moisture, the spread in CAMR is extended to larger areas during the daytime than the nighttime. The change in moisture $3 \mathrm{~h}$ before convection is not significant in region 1 .

In region 2 (the eastern sector), the pattern of CAMR (Fig. 14) is distinctly different from the mean state during both the daytime and nighttime. A clear pulse of increased moisture coming from the southeast can be observed leading toward the location of convective initiation. The horizontal extent of the moisture pulse surrounding the initiation location appears to be larger in the daytime compared to the nighttime. The location of convective initiation is also an area where the moisture changes over the previous $3 \mathrm{~h}$ are the most important. Thus, GPS-integrated moisture fields show promise as a tool to help forecast convective initiation $3 \mathrm{~h}$ prior at meso- $\beta$ and meso- $\alpha$ scales.

\section{Summary}

Precipitable water measurements made using groundbased GPS receivers are utilized to study the variation of atmospheric moisture over the continental United States at various time scales. These observations are also used to compare the water budget simulated by the NARR and to assess the link between PW and precipitation. Converting to CAMR minimizes the dependency of $\mathrm{PW}$ on topographic height. The analysis reveals the following.

1) At annual and seasonal time scales, there is high correlation between the mean CAMR from GPS and NARR. The moisture transport from the Gulf of Mexico into the Great Plains, as well as the high variability in moisture associated with the North American monsoon, are resolvable within the yearly moisture cycle. These results indicate that the both 
data sources similarly resolve the large-scale integrated water vapor fields.

2) The NARR has noticeably large offsets in CAMR at times of data assimilation (0000 and 1200 UTC). This indicates that even though the modeling system realistically reproduces the annual and seasonal water budgets, there are significant improvements to be made to properly simulate the subdaily water budget. Thus, though the water budget is adequately reproduced by the NARR at seasonal and annual scales, there are still improvements to be made to properly simulate the diurnal cycle of the water budget.

3) The diurnal moisture cycle displays significant variability across seasons. There is large spatial variation in the diurnal cycle as well. The atmospheric PW shows a distinctly different diurnal cycle in space and time over the continental United States. During the fall, winter, and spring seasons, the PW shows a transport component with a period of 2-3 days.

4) The GPS-derived CAMR products do not appear to have the same propagation structure as the precipitation. While previous works have shown a clear transport of precipitation from the Rockies to the Great Plains during warm season, this does not appear to be the case for atmospheric moisture.

5) The observations from the GPS network show that strong diurnal signal amplitude in CAMR is observed throughout the continent except at a few regions during various months. The semidiurnal signal amplitude dominates the diurnal signal over the eastern United States $\left(85^{\circ}-82^{\circ} \mathrm{W}\right)$ during the winter and spring seasons.

6) Over the Great Plains and the eastern United States, $\mathrm{PW}$ and precipitation are well correlated during the warm season and shows a phase change over the Rockies. The increase in PW after the decrease in precipitation over the Rockies is due to either the transport of moisture from the surrounding regions or strong evaporation before the precipitation reaches to ground.

7) PW and precipitation are linked distinctly in space and time over the continental United States. PW and precipitation are in phase over the Great Plains and the eastern United States during the summer season. On the other hand, over the Rockies, a phase change is observed.

8) GPS PW fields appear to provide useful information for forecasting convective initiation $3 \mathrm{~h}$ before the event at meso- $\beta$ and meso- $\alpha$ scales.

Acknowledgments. The authors express their gratitude to the SuomiNet for affording the access to the PW information and also to WDSS for providing the access to the low-altitude radar reflectivity composites. This project was undertaken with the financial support of the government of Canada provided through the Department of the Environment. The material is based upon work supported by the National Science Foundation under Awards AGS-0633587 and EAR-1042909. A special thank you goes to our group members, especially to Prof. Isztar Zawadzki for the fruitful discussions during the group meetings and to the two anonymous reviewers.

\section{REFERENCES}

Adams, D. K., and A. C. Comrie, 1997: The North American monsoon. Bull. Amer. Meteor. Soc., 78, 2197-2213, doi:10.1175/1520-0477(1997)078<2197:TNAM>2.0.CO;2.

Alber, C., R. Ware, C. Rocken, and F. Solheim, 1997: GPS surveying with $1 \mathrm{~mm}$ precision using corrections for atmospheric slant path delay. Geophys. Res. Lett., 24, 1859-1862, doi:10.1029/97GL01877.

Bevis, M., S. Businger, T. A. Herring, C. Rocken, R. A. Anthes, and R. H. Ware, 1992: GPS meteorology: Remote sensing of atmospheric water vapor using the Global Positioning System. J. Geophys. Res., 97, 15 787-15 801, doi:10.1029/92JD01517.

,,-- S. Chiswell, T. A. Herring, R. Anthes, C. Rocken, and R. H. Ware, 1994: GPS meteorology: Mapping zenith wet delays onto precipitable water. J. Appl. Meteor., 33, 379-386, doi:10.1175/1520-0450(1994)033<0379:GMMZWD>2.0.CO;2.

Braun, J., and T. Van Hove, 2005: Recent improvements in the retrieval of precipitable water vapor. ION GNSS 2005: Proceedings of the 18th International Technical Meeting of the Satellite Division of the Institute of Navigation, Institute of Navigation, 298-301.

Brown, D. W., S. J. Clarke, and J. Zabransky, 2002: A regional comparison of GPS atmospheric moisture measurements at Plymouth and Bartlett, New Hampshire. Preprints, Symp. on Observations, Data Assimilation, and Probabilistic Prediction, Orlando, FL, Amer. Meteor. Soc., P2.5. [Available online at https://ams.confex.com/ams/pdfpapers/26296.pdf.]

Carbone, R. E., and J. D. Tuttle, 2008: Rainfall occurrence in the U.S. warm season: The diurnal cycle. J. Climate, 21, 41324146, doi:10.1175/2008JCLI2275.1.

,,-- D. A. Ahijevych, and S. B. Trier, 2002: Inferences of predictability associated with warm season precipitation episodes. J. Atmos. Sci., 59, 2033-2056, doi:10.1175/ 1520-0469(2002)059<2033:IOPAWW >2.0.CO;2.

Ciesielski, P. E., and Coauthors, 2014: Quality-controlled upper-air sounding dataset for DYNAMO/CINDY/AMIE: Development and corrections. J. Atmos. Oceanic Technol., 31, 741-764, doi:10.1175/JTECH-D-13-00165.1.

Dach, R., U. Hugentobler, P. Fridez, and M. Meindl, Eds., 2007: Bernese GPS software version 5.0. Astronomical Institute of the University of Bern, Bern, Switzerland, 612 pp. [Available online at http://www.bernese.unibe.ch.]

Dai, A., and C. Deser, 1999: Diurnal and semidiurnal variations in global surface wind and divergence fields. J. Geophys. Res., 104, 31 109-31 125, doi:10.1029/1999JD900927.

_, K. E. Trenberth, and T. R. Karl, 1999: Effects of clouds, soil moisture, precipitation, and water vapor on diurnal temperature range. J. Climate, 12, 2451-2473, doi:10.1175/ 1520-0442(1999)012<2451:EOCSMP > 2.0.CO;2. 
J. Wang, R. H. Ware, and T. Van Hove, 2002: Diurnal variation in water vapor over North America and its implications for sampling errors in radiosonde humidity. J. Geophys. Res., 107, 4090, doi:10.1029/2001JD000642.

Davis, C. A., K. W. Manning, R. E. Carbone, S. B. Trier, and J. D. Tuttle, 2003: Coherence of warm-season continental rainfall in numerical weather prediction models. Mon. Wea. Rev., 131, 2667-2679, doi:10.1175/1520-0493(2003)131<2667:COWCRI >2.0.CO;2.

Davis, J. L., T. A. Herring, I. I. Shapiro, A. E. E. Rogers, and G. Elgered, 1985: Geodesy by radio interferometry: Effects of atmospheric modeling errors on estimates of baseline length. Radio Sci., 20, 1593-1607, doi:10.1029/RS020i006p01593.

Derks, H., H. K. Baltink, A. van Lammeren, B. Ambrosius, H. van der Marel, and A. Kosters, 1997: GPS water vapour meteorology: Status report. KNMI Publ. WR-97-04, 40 pp. [Available online at http://www.knmi.nl/publications/showAbstract. php?id=4790.]

Dow, J. M., R. E. Neilan, and C. Rizos, 2009: The International GNSS Service in a changing landscape of Global Navigation Satellite Systems. J. Geod., 83, 191-198, doi:10.1007/ s00190-008-0300-3.

Duan, J., and Coauthors, 1996: GPS meteorology: Direct estimation of the absolute value of precipitable water. J. Appl. Meteor., 35, 830-838, doi:10.1175/1520-0450(1996)035<0830: GMDEOT $>2.0 . \mathrm{CO} ; 2$.

Dumont, D. M., and J. Zabransky, 2001: A comparison of GPSmeasured precipitable water at Bartlett, $\mathrm{NH}$ with radiosonde measurements in the Northeast. Preprints, 11th Symp. on Meteorological Observations and Instrumentation, Albuquerque, NM, Amer. Meteor. Soc., 245-247.

Haase, J., M. Ge, H. Vedel, and E. Calais, 2003: Accuracy and variability of GPS tropospheric delay measurements of water vapor in the western Mediterranean. J. Appl. Meteor., 42, 1547-1568, doi:10.1175/1520-0450(2003)042<1547:AAVOGT>2.0.CO;2

Mesinger, F., and Coauthors, 2006: North American Regional Reanalysis. Bull. Amer. Meteor. Soc., 87, 343-360, doi:10.1175/ BAMS-87-3-343.

Nahmias, M. H., and J. Zabransky, 2004: A statistical examination and case study of integrated precipitable water (IPW) in northern New England. Preprints, Eighth Symp. on Integrated Observing and Assimilation Systems for Atmosphere, Oceans, and Land, Seattle, WA, Amer. Meteor. Soc., P1.7. [Available online at https://ams.confex.com/ams/pdfpapers/69621.pdf.]
Randel, D. L., T. H. Vonder Haar, M. A. Ringerud, G. L. Stephens, T. J. Greenwald, and C. L. Combs, 1996: A new global water vapor dataset. Bull. Amer. Meteor. Soc., 77, 1233-1246, doi:10.1175/1520-0477(1996)077<1233:ANGWVD>2.0.CO;2.

Rebischung, P., J. Griffiths, J. Ray, R. Schmid, X. Collieux, and B. Garayt, 2012: IGS08: The IGS realization of ITRF2008. GPS Solutions, 16, 483-494, doi:10.1007/s10291-011-0248-2.

Rocken, C., R. H. Ware, T. Van Hove, F. Solheim, C. Alber, and J. Johnson, 1993: Sensing atmospheric water vapor with the Global Positioning System. Geophys. Res. Lett., 20, 26312634, doi:10.1029/93GL02935.

_ - T. Van Hove, and R. Ware, 1997: Near real-time GPS sensing of atmospheric water vapor. Geophys. Res. Lett., 24, 32213224, doi:10.1029/97GL03312.

— S. Sokolovskiy, J. M. Johnson, and D. Hunt, 2001: Improved mapping of tropospheric delays. J. Atmos. Oceanic Technol., 18, 1205-1213, doi:10.1175/1520-0426(2001)018<1205: IMOTD $>2.0 . \mathrm{CO} ; 2$

Saastamoinen, J., 1972: Atmospheric correction for the troposphere and stratosphere in radio ranging of satellites. The Use of Artificial Satellites for Geodesy, Geophys. Monogr., Vol. 15, Amer. Geophys. Union, 247-251.

Schmid, R., P. Steigenberger, G. Gendt, M. Ge, and M. Rothacher, 2007: Generation of a consistent absolute phase center correction model for GPS receiver and satellite antennas. J. Geod., 81, 781-798, doi:10.1007/s00190-007-0148-y.

Surcel, M., M. Berenguer, and I. Zawadzki, 2010: The diurnal cycle of precipitation from continental radar mosaics and numerical weather prediction models. Part I: Methodology and seasonal comparison. Mon. Wea. Rev., 138, 3084-3106, doi:10.1175/ 2010MWR3125.1.

Tabios, G. Q., and J. D. Salas, 1985: A comparative analysis of techniques for spatial interpolation of precipitation. $J$. Amer. Water Resour. Assoc., 21, 365-380, doi:10.1111/ j.1752-1688.1985.tb00147.x.

Wang, J., W. B. Rossow, and Y. Zhang, 2000: Cloud vertical structure and its variations from a 20 -yr global rawinsonde dataset. J. Climate, 13, 3041-3056, doi:10.1175/1520-0442(2000)013<3041: CVSAIV $>2.0 . \mathrm{CO} ; 2$

Ware, R. H., and Coauthors, 2000: SuomiNet: A real-time national GPS network for atmospheric research and education. Bull. Amer. Meteor. Soc., 81, 677-694, doi:10.1175/1520-0477(2000)081<0677: SARNGN $>2.3 . \mathrm{CO} ; 2$. 